My A5 double-pocket wallet opens like a book with two inside gussetted pockets, which are able to take the usual hospital letter unfolded. The only item requiring folding is the large A4 hospital report. There are a number of minor advantages with this system.

The Department of Health and Social Security and the General Medical Services Committee have already given their opinions on the new A4 record size folder for general practice. About $90 \%$ of medical records in general practice do not require the large A4 hospital size of record. The A5 folder would be immensely less expensive and more convenient in the office and cheaper to produce and reduce conversion costs in practice.

Dr. Gillian Strube's second point was the change to a numerical system of filing. This has been tried in a few practices and although I have not been persuaded of its value, it is a system any general practitioner can use without inconveniencing any others.

I do not agree that the A4 folders need take up no more floor space than the old medical record envelopes. The A4 folders are large, bulky, and take up more than twice as much room.

I agree that the computer storage of records for general practice is a long way off and may never occur in ordinary general practice. I also have many personal doubts as to whether this system is in the interests of the patient, particularly when confidential information is being recorded.-I am, etc.,

Worcester

\section{A. J. Laidlaw}

SIR,-Before 20,000 general practitioners find themselves persuaded by the enthusiasts such as Dr. J. K. Hawkey and others (11 December 1971, p. 667) and Dr. Gillian Strube (19 February, p. 513) and by the administrators that a larger (A4) size of record folder is desirable they should consider some of the defects of larger folders apart from the obvious one of sheer bulk. Worst of all defects is that they allow or actually encourage the accumulation of rubbish which is already too comm $r n$ in collections of medical notes both in hospital and outside.

I have recently started to collect gems from general practice notes, such as that dated 1949 saying "I would be grateful for a reply to my letter of three months ago" and still filed 22 years later (did he ever get a reply?); such gems abound. Then there is the series of letters which read "Mr. A has a hernia: I will repair it": "I have just repaired Mr. A's hernia"; "Mr. A has left hospital after his hernia repair"; and "Mr. A has recovered from his hernia"-only one of which need usually be kept. Then again, there is the string of letters which say that $\mathrm{Mr}$. B is making satisfactory progress and will be seen again soon, each of which supersedes its predecessor. Larger folders mean less incentive to consign these superfluous letters to the waste paper basket.

Another disadvantage of bigger folders is that they encourage the use of backing sheets as permanent mounts for laboratory reports of ephemeral value. I have recently received a set of notes from a doctor who is a distinguished exponent of the virtues of larger folders. I increased the value of the notes in reducing them to a third of their previous bulk by removing a large, tough backing sheet and most of its adherent haemoglobin reports which had been collected during a pregnancy which ended a year ago. The reports had been valuable then but were now too numerous to be studied afresh each time; just two, unmounted, were sufficient to show later doctors the general trend. Devices like backing sheets are impressive at the time but we must remember that any plan we follow must allow for 50 years or more of the accumulation of information.

I suggest, Sir, that if any patient's old general practice (or hospital?) notes have become too numerous or too bulky to fit into the present $5 \times 7 \frac{1}{2}$ inch $(12 \times 18 \mathrm{~cm})$ record envelope they are too numerous to be read except on very rare occasions, and will take so much time to digest that they will detract from the care of other patients. They may as well be put, complete, untouched, into the dustbin (also, presumably, size A4).-I am, etc.,

Southampton

John L. STRUthers

\section{Confusion of Ampoules}

SIR,-A recent report in the national press (Daily Express, $8 \mathrm{March}$ ) of an ampoule of morphine being found alongside a vial of penicillin in general practice instead of distilled water prompts me to draw attention to a practice that I have carried out for years. When prescribing penicillin preparations for injection I always specify the water in $5 \mathrm{ml}$ ampoules. The basic price is only a fraction of a penny more than the $2 \mathrm{ml}$, but it ensures that there can be no confusion with any other $2 \mathrm{ml}$ ampoules which during its life in a visiting bag may lose its markings. - I am, etc.,

London N.W.10

Denys E. Howells

\section{Discontinuation of Evening Surgery}

SIR,-My practice decided to dispense with evening surgeries for all time two years ago. The decision gave cause for considerable but yet not unsurmountable resentment. This major reform of our practice routine would have enjoyed a much less grudging acceptance than it did had it not been considered by the local press as a dastardly retrograde step.

Press hostilities culminated in criticism of myself and colleagues in the national daily newspapers. Ironicallv, the net results of these reports has been that other doctors have become intrigued and they have inquired as to how we effected our changes and the nature of the difficulties we encountered.

My partners and I hope that our experiences will encourage many more general practitioners to reappraise their practice arrangements. We are the first to recognize that the changes we have implemented cannot be adopted universally, and we do not necessarily advocate universal application. Many general practitioners have hospital and other appointments outside general practice and their practice rourine is arranged accordingly. However, we are convinced that there are also many general practitioners who have evening surgeries more through force of habit and the fear of untrodden paths than for patient needs.

Our reorganized day has brought us immeasurable benefits. We have now a regular eight-hour day (9 a.m.-5 p.m.), which, incidentally, is also a sound business proposition, and we have filled the gaps between morning and afternoon surgeries with home visiting and a variety of new clinic sessions. We are much happier in our work and more efficient. Our families have suddenly become aware of our physical existence and we can to some extent participate in regular pastimes. It has been our experience that the health of our patients has not been adversely affected by the absence of evening surgeries.

All this has been achieved without detriment to our 24-hour responsibility.-I am, etc.,

Partington

T. TERNENT

Manchester

\section{Radiological Equipment}

SIR,-As a radiologist in a busy hospital, I am becoming increasingly exasperated with the unreliability and over-sophistication of the modern $x$-ray apparatus which we are forced to buy. We are in the hands of the manufacturers who, year by year, add to the complication of their machinery.

Soon after installation of our very expensive new apparatus we began to suffer failure of the gadgetry which revealed multiple defects in design and manufacture. We also discovered deficiencies in service facilities and unavailability of replacement parts, whch can be the most damaging feature of all. At a time when the demand for $x$-ray examinations is rising at $10 \%$ per annum, we are constantly in danger of being unable to fulfil our commitments owing to endless equipment failure.

The manufacturers have provided us with some excellent equipment in the past which has enabled us to cope with an everincreasing work-load, but now they seem to be more concerned with promoting unreliable electronic trickery than with providing soundly designed and robust apparatus with a long working life.

It is high time that the Department of Health established a radiological laboratory to test all the new apparatus before it is purchased for the National Health Service, and equipment thus tested should be given an appropriate certificate.-I am, etc.,

Ipswich, Suffolk

J. W. MILLS

SIR,-It is debated whether general practice can constitute an academic discipline. ${ }^{1}$ Dr. W. Anthony Ball evades the debate (19 February, p. 513) while denigrating the lecturer in general practice because he is "an academic." However, Professor A. P. M. Forrest has recently defined the academic as one who works in a university department. ${ }^{2}$ To be an academic is therefore a concomitant of, and not a prerequisite for, a university appointment.

In any general practice the three elements of service, teaching, and research are not mutually exclusive. This is reflected in the work of academic departments of general 
practice. The pursuit by a doctor of a research or teaching interest is not inimical to a service commitment.

The primary teaching responsibility of the departments is for the undergraduate phase, since much of the work of vocational and continuing education is undertaken more frequently, and perhaps more appropriately, outside the departments. The contribution of a lecturer to the teaching, service, and research work of a department will vary with his experience. Even if he has only completed a general practice vocational training he will already be four years post-graduation. His four years will have been wasted if at this stage he has nothing to teach the undergraduate about diagnosis in general practice, continuity of care, the doctor-patient relationship, the social effects of disease, etc.

Any academic department has a responsibility for the in-service education and training of its members. The Royal College of General Practitioners has suggested that the fifth postgraduate year of training for general practice might be appropriately spent in further study of the behavioural sciences, epidemiology, sociology, or medical statistics in the context of general practice. ${ }^{34}$ At the present time posts which even approximate to this concept of "senior registrar in general practice" are only to be found in departments of general practice. A lecturer in general practice may therefore have only limited general practice experience at the time of his appointment. I am, etc.,

Edinburgh

PhILIP L. Heywood

1 McWhinney, I R., Lancet, 1956, 1, 419 .

2 Forrest, A. P. M., Scottish Medical fournal, 1971, $16,463$.

3 Royal College of General Practitioners, Reports from General Practice, No. 1. London, R.C.G.P., 1965. Royal College of General Practitioners, Reports
from General Practice, No. 6. London, R.C.G.P.,
1967.

\section{Ambulance Noise}

SIR,-May I, as accident medical officer to Bath Fire Brigade and Ambulance Service, be permitted to reply on behalf of the emergency services to Dr. J. H. Henderson's letter on ambulance noise (11 March, p. 694).

When attending an accident, emergency, or fire the driver of an emergency vehicle has two alternatives: to progress as an unidentified vehicle in the ordinary traffic flow and wait in queues, or to avoid undue delay and maintain a course that takes his vehicle safely through traffic at a speed slightiy faster than that of the prevailing traffic flow. To answer an emergency call, seldom knowing any detail of the incident except the location, surely involves the second alternative, and to this end the Home Office lays down attendance times for fire appliances to reach an incident in a given fire risk category.

In conjunction with the Fire and Ambulance Service I have just completed a university research project on the provision of medical aid at the scene of accidents. One of the findings was that the time taken by the emergency services to arrive at the scene was very important with regard to the survival of the seriously injured. Similarly, early arrival prevented the mishandling of patients by persons untrained in first aid who, though well intentioned, were seen to have worsened the patients' injuries on at least two occasions. Because of the more immediate effect of an audible warning as compared with visual identification the former can be essential under certain traffic conditions both for reasons of safety and prevention of unnecessary delay.

In my experience of working closely with all three emergency services in the last nine years I recognize the degree of responsibility with which these vehicles are driven, and how infrequently they are involved in accidents. Any drama attached to such occasions is related more to portrayal on films and television than in real life. The noise of an alternating emergency horn is not unpleasant, and is of short duration in passing any one person, and surely represents an insignificant disturbance in relation to the benefit to those involved in the emergency. It has for instance been reported in the press that people trapped by fire have delayed jumping from high buildings on hearing the approach of the emergency vehicles. (Leinster Towers Hotel fire, London, 6 June 1969.)

The class of emergency and speed with which a doctor can be found to attend an incident does not always correspond with that of the emergency services, though where doctors have formed groups to attend accidents they are already using the B.M.A. green flashing light.-I am, etc.,

Dunkerton, Bath

R. SNOOK

\section{Legislative Power}

SIR,-I have read very carefully the report by the Central Committee for Hospital Medical Services (Supplement, 4 March, p. 56). In the latter part of the eighteenth century the historian Edward Gibbon wrote (I quote from memory), "The principles of a free constitution are irrecoverably lost when the legislative power is ncminated by the executive." I suggest, $\mathrm{Sir}$, that the issue under discussion by the Central Com-

\section{Impartiality of "B.M.J."}

SIR,-Your Apology (4 March, p. 633) is of the greatest importance for it has brought to light an episode which calls into question the impartiality of the British Medical fournal in medicopolitical affairs. To understand the implications your readers should know the whole story.

On 1 January 1972, the B.M.F. reported (Supplement, p. 1) that the Central Committee for Hospital Medical Services, at its meeting on 16 December 1971, had decided to oppose the application of the Regional Hospitals Consultants and Specialists Association for representation on the Joint Consultants Committee. Mr. S. C. Simmons spoke against the decision in the debate. On 7 January I submitted for publication in the Journal a letter attacking the decision, but when I examined a proof which was sent to me on 17 January I saw that my letter had been altered, and as the Editor was not prepared to publish it in its original form I withdrew it. Twelve days later a letter from Dr. C. E. Astley, Chairman of the C.C.H.M.S., appeared in the Journal (29 January, p. 315). It purported to be an answer to statements made by Mr. S. C. Simmons in the C.C.H.M.S. debate, but a mittee is exactly that to which Gibbon refers, and that, if the statement was true when Gibbon wrote it, it is equally true today. No sophistry can assail it.-I am, etc.

Gibraltar

T. KNOWLES BONEY

\section{Doctors and Overpopulation}

SIR,-Mr. H. G. E. Arthure's letter (26 February, p. 566) only emphasizes the point that we made (5 February, p. 377) on the struggle there has been to get contraceptive instruction to midwives. He states, as we are well aware, that this was introduced by the Central Midwives Board in 1968. It is a good thing some of us were teaching midwives on the subject of family planning before this date. Never mind the question of overpopulation; it has been one of the axioms of obstetrics that mothers should have at least two-year gaps between the births of their babies, but how little advice has been given over the years to enable them to achieve this.

In the third paragraph of his letter, Mr. Arthure states "that the Board does not include the practical application of contraceptive methods in its syllabus but encourages midwives to attend Family Planning Association courses." We agree that this is a move in the right direction, but it does leave this essential training of midwives as an optional part of their course

We appreciate that advice on techniques of contraception and sterilization is essentially the province of the doctor, but as the community nursing staff becomes more closely attached to family doctors and hospitals they should be playing their full part in assisting parents to plan their children. -We are, etc.,

SHIRLEY NICHOLAS P. NICHOLAS

Wirral, Cheshire

cursory examination revealed that they were statements Mr. S. C. Simmons had not made. Tine truth of the matter was that without my knowledge my unpublished letter had been shown to the C.C.H.M.S. Chairman, Dr. Astley, who had thus been given an opportunity of commenting upon it before its scheduled publication. It was in answer to my letter that Dr. Astley had written. Mr. S. C. Simmons, who had been wrongly accused of having said something he had not, was indignant and wrote a letter to the Journal which refuted Dr. Astley's allegations and answered points Dr. Astley had raised. This letter has yet to be published; instead, on 4 March, your Apology appeared.

The episode has demonstrated that chairmen of B.M.A. committees may be shown letters sent to the Journal before publication and without the author's knowledge. Why was Dr. Astley shown my letter? One member of the Journal's editorial staff told me that all letters on medicopolitical subjects are shown to the Secretariat so that "errors of fact can be corrected by a footnote," but Dr. Astley is not a member of the Secretariat. I accept that the Journal will be more readable if questions put by correspondents 